\title{
CFRP reinforcement adhesive joint performance on the transversely damaged steel elements under axial tension
}

\author{
Alexander Danilov ${ }^{1 *}$ \\ ${ }^{1}$ Moscow state university of civil engineering, Yaroslavskoye shosse, 26, Moscow, Russia, 129337
}

\begin{abstract}
The analytic solution for analysis and design of bonded CFRPreinforcement of tension elements with discontinuity type damage are presented. Analytical expressions are obtained from integrating a homogeneous second-order differential equation describing the equilibrium in the adhesive layer. A simplified equilibrium model is considered with only shear stresses in the adhesive layer taken into account. Comparison of numerical results obtained on the basis of analytical expressions and on the basis of FEM in the MSC Nastran software is performed. The graphical and tabular dependences for the joint adhesive layer parameters are presented. It is shown that the bearing capacity of the adhesive joint is significantly influenced not only by the strength of the glue, but also, and to a great extent, by its shear modulus. The corresponding effective length of the adhesive layer is calculated which increase does not result in the bearing capacity of the joint increase.
\end{abstract}

\section{Introduction}

The traditional approach in repair of corroded or mechanically damaged steel structures is to cut out the damaged areas and replace them with new steel elements using welded and bolted connections, which requires considerable labor, takes a lot of time, and may sometimes require the use of heavy Lifting equipment. Steel reinforcement elements increase the structural weight and are susceptible to corrosion, and there also additional stress concentration zones appear in base metal resulting of welding or drilling [1]. Welding involves additional problems of quality control of welded joints, welding in hard-to-reach places, welding residual stresses, cracking in welded zones subject to heating, and a significant decrease in fatigue strength [2]. The welding application in a highly explosive environment is possible only if strict safety precautions are taken with prolonged interruptions of the object normal operation resulting in a dramatic uplift in the repair cost [3].

Along with the traditional methods of reinforcing steel structural elements using the welded and bolted joints, the application of carbon fiber based polymer materials (CFRP) may prove effective providing just slight increase in weight of the structure, no loss in cross sections, no stress concentration or additional potential corrosion sites, and less laborintensive reinforcement process compared to that with steel elements. CFRPs are of high

\footnotetext{
*Corresponding author: alenk904@mail.ru
} 
strength and wear resistance and the resistance to aggressive environment as well. The weight of carbon fiber material is multiple times lower than that of steel plates of similar amplification [4]. At that, the resistance of the carbon fiber to stretching is many times higher than that of steel, and the Young's modulus may be close to or even much higher than that of steel [5]. The application of CFRPs in building structures strengthening is also considered in [6-15].

This paper concerns the axially stretched steel elements of truss or brace systems with significant damages such as transverse cracks. In the numerical examples the ultimate case of cross-section completely disabled is considered for a steel strip. The calculation methods and conclusions are applicable for the symmetrically strengthened elements of any cross section under axial tension.

\section{Analytical expressions}

The equilibrium conditions of the element of adhesion layer of the glued joint lead to the differential equation in the form (1)

$$
\tau^{\prime \prime}-\beta^{2} \tau=0,
$$

where $\tau$ - shear stress in the adhesive layer; $G_{a}$-adhesive shear modulus; $t_{a}$-adhesive layer thickness; $b_{p}$ - width of the adhesive layer and CFRP tape; $d$ - length of the adhesive layer on one side of the joint; $E_{s}$ - elasticity modulus of the tension element material; $A_{s}$ - crosssection area of tension element; $E_{p}$ - elasticity modulus of the CFRP material; $A_{p}$ - crosssection area of CFRP material.

$$
\beta^{2} \equiv \frac{G_{a}}{t_{a}} b_{p} \cdot\left(\frac{1}{E_{p} A_{p}}+\frac{1}{E_{s} A_{s}}\right)
$$

The solution of this equation follows

$$
\begin{gathered}
\tau(x)=P\left(B_{11} \operatorname{sh}(\beta x)+B_{21} \operatorname{ch}(\beta x)\right) \\
B_{11}=-\frac{G_{a}}{\beta \cdot t_{a}} \cdot \frac{1}{E_{s} A_{s}} \quad B_{21}=\frac{\beta}{b_{p}} \cdot \frac{1}{\operatorname{sh}(\beta d)}+B_{11} \cdot \frac{1-\operatorname{ch}(\beta d)}{\operatorname{sh}(\beta d)}
\end{gathered}
$$
from

The tension force in the CFRP reinforcement tape at the gluing length may be defined

$$
N_{p}(x)=P \cdot \frac{b_{p}}{\beta} \cdot\left(\left(B_{11} \operatorname{ch}(\beta x)-1\right)+B_{21} \operatorname{sh}(\beta x)\right)
$$

The $x$ coordinate is measured from the left end of the gluing length on the left side of connection.

From the condition (5) of limiting shear stresses in the adhesive, it is easy to obtain a constraint on the applied force $P$.

$$
\tau(x)=P \cdot\left[B_{11} \operatorname{sh}(\beta x)+B_{21} \operatorname{ch}(\beta x)\right] \leq R_{a s}
$$

\section{Numerical studies}

To analyze the behavior of such connections, an example of the connection of two steel plates is considered, the gap between them is overlapped on both sides by high-strength tapes (based on carbon fiber and similar materials) pasted on them (Fig. 1). A tensile force of $40000 \mathrm{~N}(\approx 4 \mathrm{t})$ is applied to the joint. All other parameters of the model are given below. The results are presented in Fig. 2-9.

Connection parameters: 
- Combined plates are each $195 \mathrm{~mm}$ long, $10 \mathrm{~mm}$ gap, steel C255, cross section 50x5. The yield stress tension resistance the of steel is $50 \times 5 \times 250=62500 \mathrm{~N} \approx 6.25 \mathrm{t}$, and ultimate stress resistance is $50 \times 5 \times 370=92500 \mathrm{~N} \approx 9.25 \mathrm{t}$

- The top and bottom CFRP tapes $200 \mathrm{~mm}$ length are taken each of 50x1 mm cross-section $\left(E_{p}=300 \mathrm{GPa}, R_{p u}=2000 \mathrm{MPa}\right)$. Then $2000 \mathrm{MPa} \times 50 \mathrm{~mm} 2=100000 \mathrm{~N} \approx 10 \mathrm{t}$ is the ultimate tension force for one tape

- The adhesive layer length on one side of the joint is $95 \mathrm{~mm}$, the total cross-section is $2 \times 50 \times 1 \mathrm{~mm}^{2}$ (the shear module $G_{a}$ was taken successively at 50,100, 200, 400, 700, 1000,2000 and $3000 \mathrm{MPa}$, the shear strength $R_{\mathrm{as}}$ in all variants is $15 \mathrm{MPa}$ )

- The tensile force applied to the steel strip is $40000 \mathrm{~N}$

- The tensile stresses in the carbon fiber tape in the gap are $40000 /(2 \times 50 \times 1)=400 \mathrm{Mpa}$.

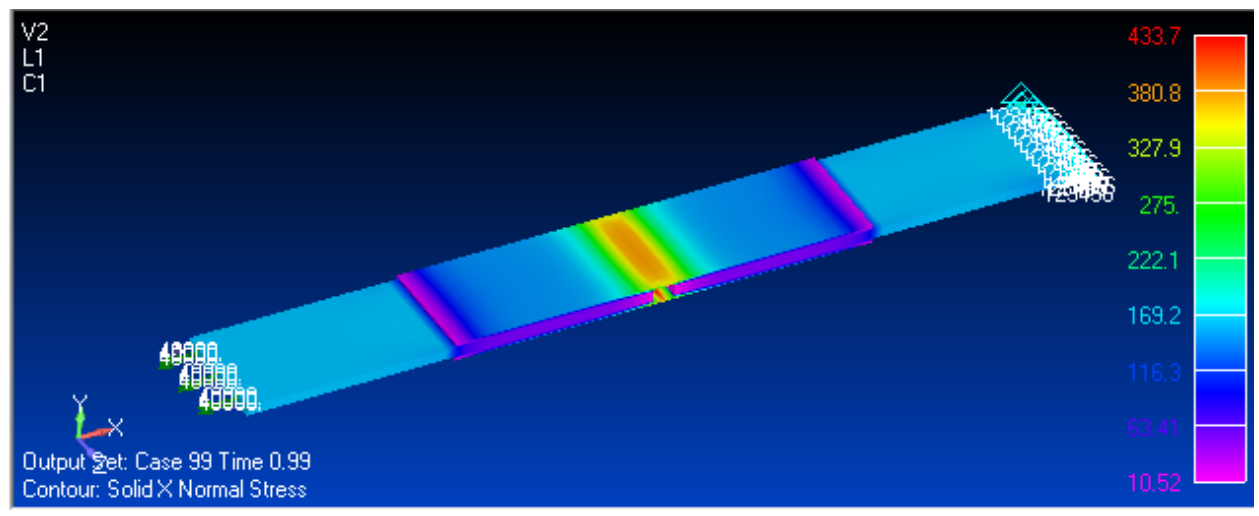

Fig. 1. FE Model of joint

Below (Fig. 2-9) are the results of calculating the shear stresses in the adhesive (the top glue layer to the left of the gap) for different values of the shear modulus obtained with the MSC Nastran software (left) and using the MS EXCEL program (right) with the formulas (2-6) obtained by integration the differential equation (1).
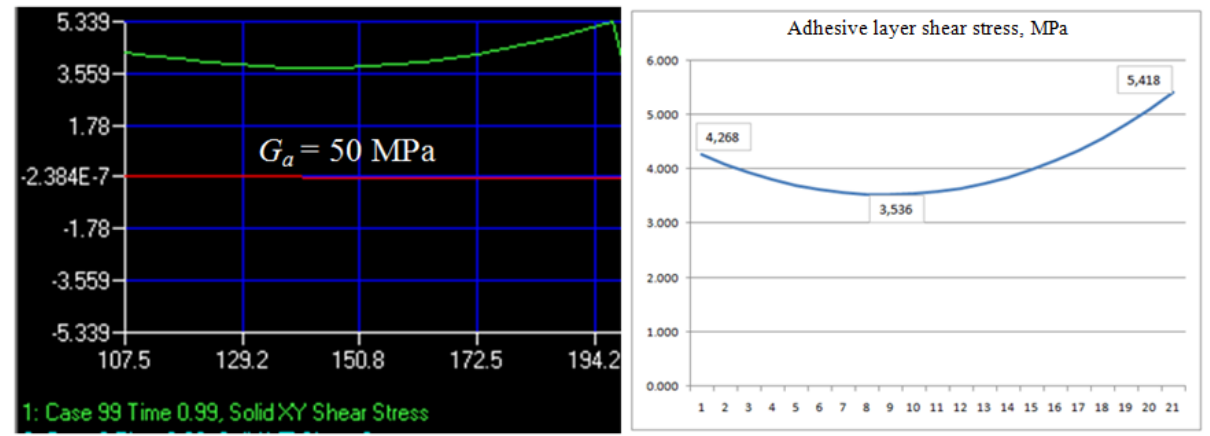

Fig. 2. $\tau$ in adhesive versus its length for $G \mathrm{a}=50 \mathrm{Mpa}$ (on the left - Nastran, right - analytical) 

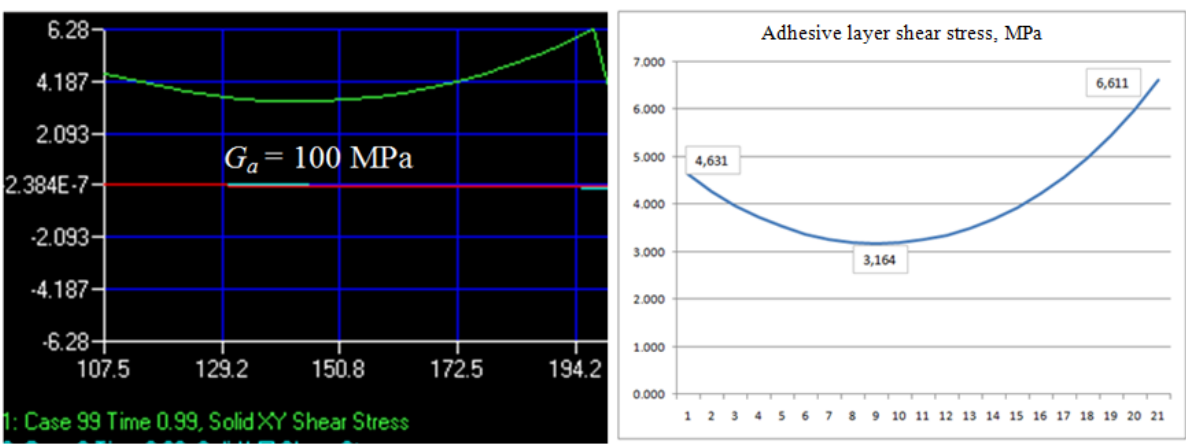

Fig. 3. $\tau$ in adhesive versus its length for $G \mathrm{a}=100 \mathrm{Mpa}$ (on the left - Nastran, right - analytical)
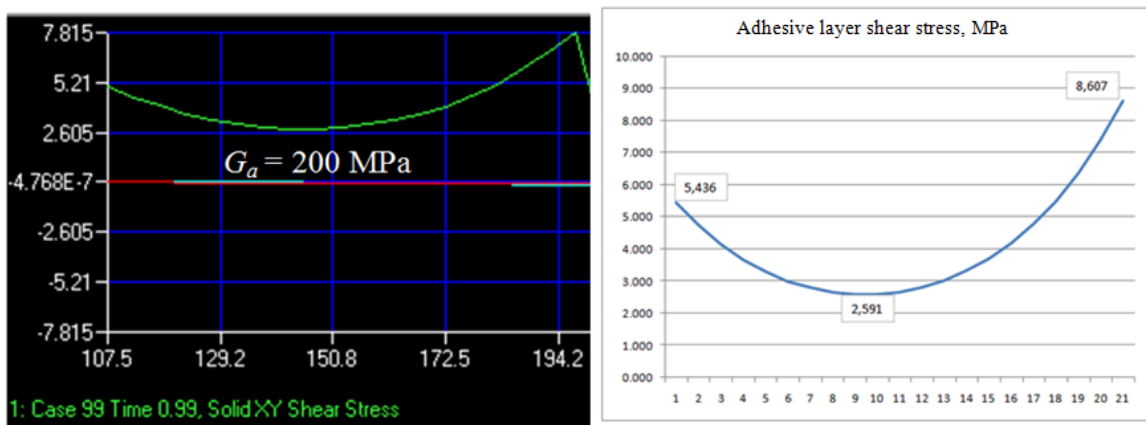

Fig. 4. $\tau$ in adhesive versus its length for $G \mathrm{a}=200 \mathrm{Mpa}$ (on the left - Nastran, right - analytical)
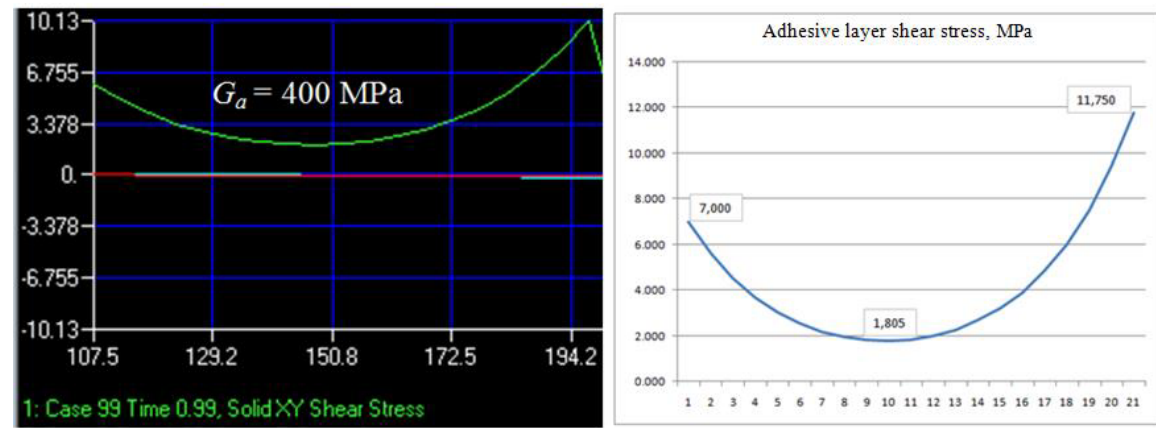

Fig. 5. $\tau$ in adhesive versus its length for $G \mathrm{a}=400 \mathrm{Mpa}$ (on the left - Nastran, right - analytical)
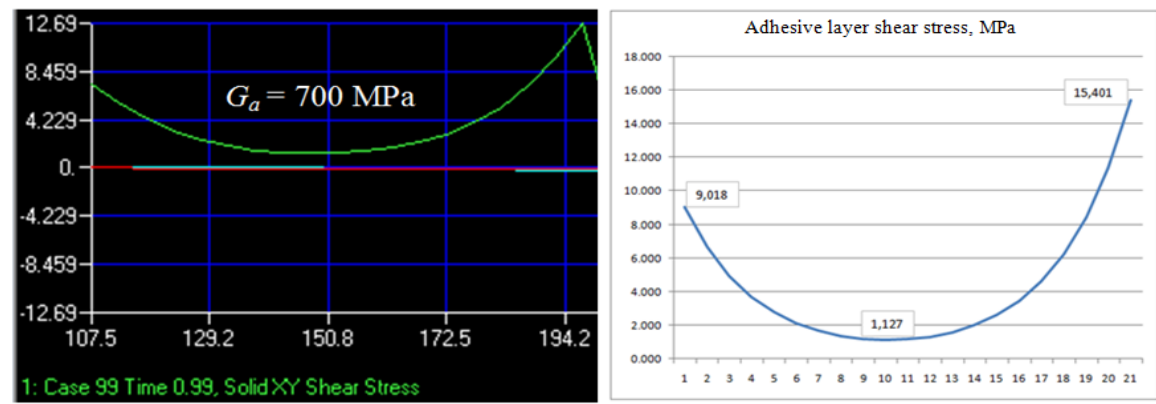

Fig. 6. $\tau$ in adhesive versus its length for $G \mathrm{a}=700 \mathrm{Mpa}$ (on the left - Nastran, right - analytical) 

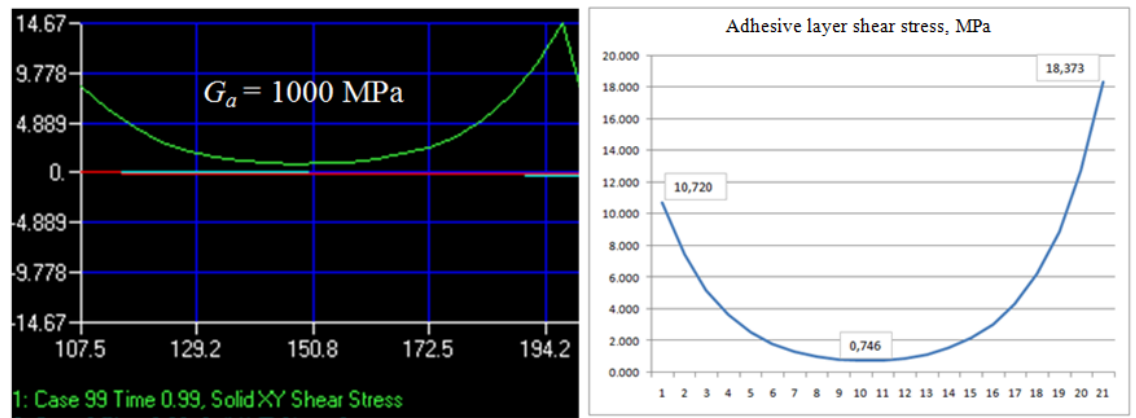

Fig. 7. $\tau$ in adhesive versus its length for $G \mathrm{a}=1000 \mathrm{Mpa}$ (on the left - Nastran, right - analytical)
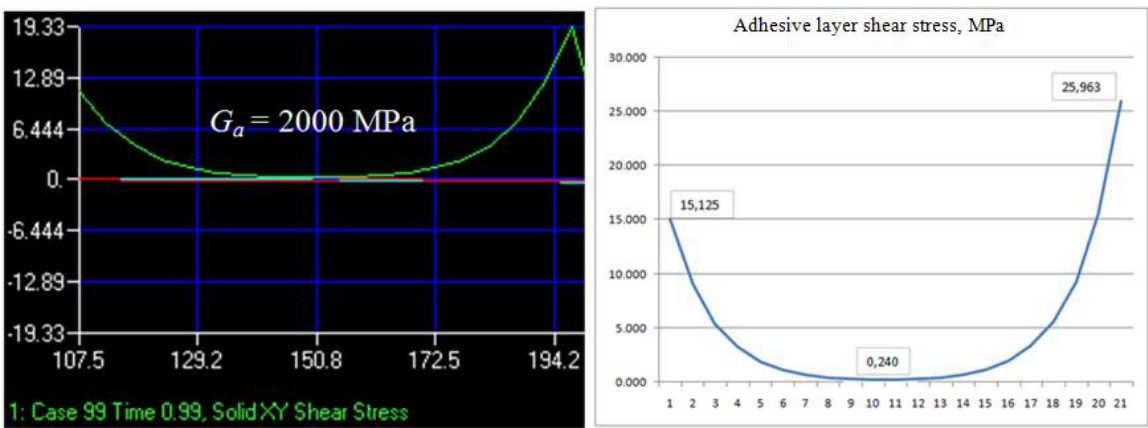

Fig. 8. $\tau$ in adhesive versus its length for $G \mathrm{a}=2000 \mathrm{Mpa}$ (on the left - Nastran, right - analytical)
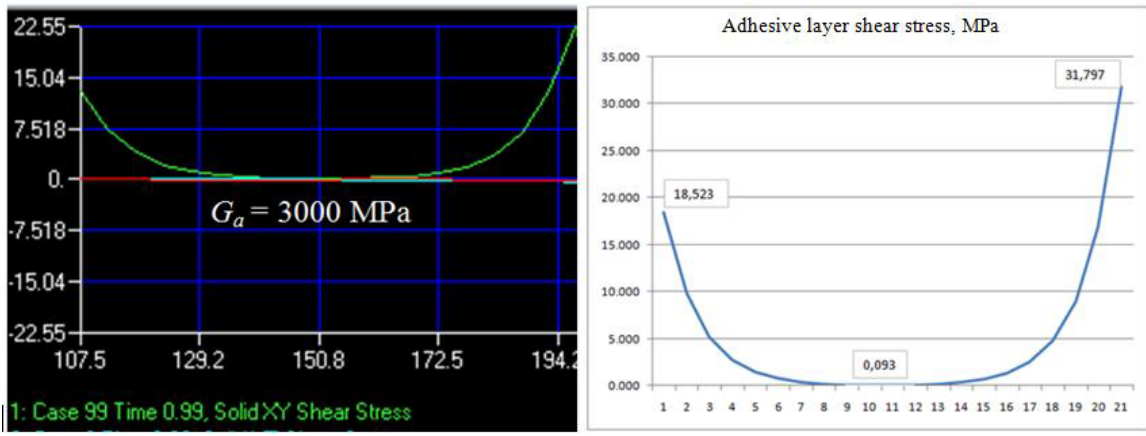

Fig. 9. $\tau$ in adhesive versus its length for $G \mathrm{a}=3000 \mathrm{Mpa}$ (on the left - Nastran, right - analytical)

Based on the analytical solution, it is quite easy to obtain numerically a number of useful dependencies: ultimate value of the tensile force $P_{\text {ult }}$ versus shear modulus $G_{\mathrm{a}}$ for a fixed values of the shear strength $R_{\mathrm{s}}$ and the length of gluing (Table 1), and the shear design resistance of the adhesive joint $P_{\text {ult }}$ and the corresponding minimum allowable length of gluing $d_{\min }$ versus shear modulus $G_{\mathrm{a}}$ (Table 2). The minimum allowable length of gluing $d_{\text {min }}$ should provide the strength of glue connection and may be easily obtained for any allowable (for all joint elements) value of $P \leq P_{\text {ult }}$. For example, with the shear strength of the adhesive $R_{\mathrm{s}}=15 \mathrm{MPa}$ and the gluing length of $100 \mathrm{~mm}$ the dependence is: 
Table 1. Shear resistance of the adhesive joint $P_{\text {ult versus shear modulus } G_{\mathrm{a}}}$

\begin{tabular}{|l|c|c|c|c|c|c|c|c|}
\hline$G_{\mathrm{a}}, \mathrm{MPa}$ & 50 & 100 & 200 & 400 & 700 & 1000 & 2000 & 3000 \\
\hline$P_{\mathrm{ult}}, \mathrm{N}$ & 109752 & 90755 & 69712 & 51065 & 38960 & 32657 & 23110 & 18870 \\
\hline
\end{tabular}

The results of calculations on the basis of analytical solution of minimum gluing length $d_{\text {min }}$, providing the maximum joint shear resistance for the shear strength of the adhesive layer of $15 \mathrm{MPa}$, is shown in Table 2:

Table 2. Minimum gluing length $d_{\min }$ and $P_{\text {ult }}$ versus shear modulus $G_{\text {a }}$

\begin{tabular}{|l|c|c|c|c|c|c|c|c|}
\hline$G_{\mathrm{a}}, \mathrm{MPa}$ & 50 & 100 & 200 & 400 & 700 & 1000 & 2000 & 3000 \\
\hline$d_{\text {min }}, \mathrm{mm}$ & 656 & 545 & 358 & 256 & 169 & 147 & 119 & 91 \\
\hline$P_{\text {ult }}, \mathrm{N}$ & 146161 & 103354 & 73082 & 51677 & 39064 & 32683 & 23111 & 18870 \\
\hline
\end{tabular}

Further increase in the length of the gluing does not lead to increase in $P_{\text {ult. }}$. It follows from Table 2 that with an increase in the shear modulus, the rational length of the gluing decreases sharply, that is, as show the shear stress distribution diagrams on fig. 2-9, the effective zone of the adhesive layer concentrates at its ends. In Table 3 the $P_{\text {ult }}$ and the corresponding effective length of the adhesion layer $d_{\text {eff }}$ versus glue shear strength $R_{\text {as }}$ are presented for the shear modulus value of $G_{\mathrm{a}}=100 \mathrm{MPa}$.

Table 3. $P_{\text {ult }}$ and effective length of adhesion $d_{\text {eff }}$ versus $R_{\text {as }}$

\begin{tabular}{|l|c|c|c|c|c|c|c|c|}
\hline $\begin{array}{l}R_{s} \text { клея, } \\
\mathrm{MPa}\end{array}$ & 2 & 5 & 7 & 10 & 13 & 15 & 17 & 20 \\
\hline$d_{\text {eff }}, \mathrm{mm}$ & 580 & 471 & 464 & 459 & 457 & 456 & 455 & 454 \\
\hline$P_{\text {ult }}, \mathrm{N}$ & 13781 & 34451 & 48231 & 68901 & 89571 & 103351 & 117131 & 137801 \\
\hline
\end{tabular}

For the shear modulus of $G_{\mathrm{a}}=100 \mathrm{MPa}$ and shear strength of the adhesive $R_{s}=15 \mathrm{MPa}$, the maximum allowed applied force $P_{\text {ult }}$ versus gluing length $d$ is shown in Table 4:

Table 4. Maximum allowed applied force $P_{\text {ult }}$ versus gluing length $d$

\begin{tabular}{|l|c|c|c|c|c|c|c|c|}
\hline$d, \mathrm{~mm}$ & 456 & 400 & 300 & 200 & 150 & 100 & 50 & 10 \\
\hline$P_{\text {ult }}, \mathrm{N}$ & 103361 & 103342 & 103231 & 102129 & 99451 & 90755 & 63233 & 14883 \\
\hline
\end{tabular}

It is easy to see that here, even with a more than twofold decrease in the length of gluing, the bearing capacity of the joint reduces insignificantly.

These results are of practical importance, since they allow to significantly reduce the surface area of steel, which requires special preparation for gluing the reinforcement elements, which can provide a significant economic effect when repairing and strengthening the stretched elements due to a reduction in material consumption, labor and time.

\section{Conclusions}

1. There is a correlation of numerical data based on the analytical solution and using FEM

2. Calculation by formulas gives higher values of the maximum shear stresses in the glue than the FEM, since the closed solution is based on the simplified approach

3. Reduction of the adhesive shear modulus leads to an increase of bearing capacity of the adhesive joint at the same shear strength of the adhesive

4. This is due to a more uniform distribution of shear stresses along the length of connection with the decrease of the shear modulus value

5. In different material specifications not only the strength of the glue should be indicated, but also the corresponding shear modulus and Poisson ratio, since the adhesive strength alone does not determine the bearing capacity of the adhesive bond completely

6. The analytical solution makes it possible to select the parameters of glued joints for the subsequent refined calculations in specific application cases with minimal effort. For 
example, the most effective combination of glue parameters such as shear resistance and shear modulus.

\section{References}

1. M. Tavakkolizadeh, H. Saadatmanesh, Fatigue strength of steel girders strengthened with carbon fiber reinforced polymer patch. Journal of Structural Engineering, ASCE, 129, 186-196 (2003)

2. S. El-Tawil, E. Ekiz, S. Goel, S.-H. Chao, Retraining local and global buckling behavior of steel plastic hinges using CFRP. Journal of Constructional Steel Research, 67, 261-269 (2011)

3. N. G. Tsouvalis, L. S. Mirisiotis, D. N. Dimou, Experimental and numerical study of the fatigue behaviour of composite patch reinforced cracked steel plates. International Journal of Fatigue, 31, 1613-1627 (2009)

4. A. Shaat, D. Schnerch, A. Fam, S. Rizkalla, Retrofit of Steel Structures Using Fiber Reinforced Polymers (FRP): State-of-the-Art. Centre for Integration of Composites into Infrastructure (2003)

5. T.-C. Nguyen, Y. Bai, X.-L. Zhao, R. Al-Mahaidi, Mechanical characterization of steel/CFRP double strap joints at elevated temperatures. Composite Structures, 93, 1604-1612 (2011)

6. I.I. Ovchinnikov, I.G. Ovchinnikov, G.V. Chesnokov, D.A. Tatiyev, D.V. Pokulayev, Usilenie metallicheskih konstrukziy fibroarmirovannymi plastikami, Internet-jurnal Naukovedeniye, Vypusk 3, may - june (2014)

7. M. Bocciarelli, P. Colombi, G. Fava, and C. Poggi, Fatigue performance of tensile steel members strengthened with CFRP plates, Composite Structures 87 334-343 (2009)

8. H. Liu, R. Al-Mahaidi, and X. Zhao, Experimental study of fatigue crack growth behaviour in adhesively reinforced steel structures, Compos. Struct. Vol. 90, pp. 12-20 (2009)

9. K. A. Harries, A. J. Peck, and E. J. Abraham, Enhancing stability of structural steel sections using FRP, Thin-Walled Structure. Vol. 47, pp. 1092-1101 (2009)

10. A.K. Patnaik, and C. L. Bauer, Strengthening of steel beams with carbon FRP laminates, Proceeding of the 4th Advanced Composites for Bridges and structures conference, Calgary, Canada (2004)

11. P. Colombi, A. Bassetti, A. Nussbaumer, Analysis of cracked steel members reinforced by prestressed composite patch, Fatigue Fract Eng Mater Struct, Vol. 26, No. 1, pp. 59-67 (2003)

12. B. Täljsten, C.S. Hansen, J.W. Schmidt, Strengthening of old metallic structures in fatigue with prestressed and non-prestressed CFRP laminates. Construction and Building Materials, 23(4), pp. 1665-1677 ( 2009)

13. E. Ghafoori, M. Motavalli, J. Botsis, A. Herwig, M. Galli, Fatigue strengthening of damaged metallic beams using prestressed unbonded and bonded CFRP plates. International Journal of Fatigue, 44, pp. 303-315 (2012)

14. E. Ghafoori, A. Schumacher, M. Motavalli, Fatigue behavior of notched steel beams reinforced with bonded CFRP plates: Determination of prestressing level for crack arrest, Engineering Structures, 45, pp. 270-283 (2012)

15. E. Ghafoori, M. Motavalli, Flexural and interfacial behavior of metallic beams strengthened by prestressed bonded plates, Composite Structures, 101, pp. 22-34 (2013) 